\title{
Neuronal excitation upregulates Tbr1, a high-confidence risk gene of autism, mediating Grin $2 b$ expression in the adult brain
}

\author{
Hsiu-Chun Chuang 1,2, Tzyy-Nan Huang ${ }^{2}$ and Yi-Ping Hsueh ${ }^{1,2} *$ \\ ' Graduate Institute of Life Sciences, National Defense Medical Center, Taipei, Taiwan \\ 2 Institute of Molecular Biology, Academia Sinica, Taipei, Taiwan
}

\section{Edited by:}

Dirk Schubert, Radboud University

Nijmegen Medical Centre,

Netherlands

Reviewed by:

Hermona Soreq, The Hebrew University of Jerusalem, Israel

Nael Nadif Kasri, Radboud University

Nijmegen Medical Centre,

Netherlands

\section{${ }^{*}$ Correspondence}

Yi-Ping Hsueh, Institute of Molecular Biology, Academia Sinica,

128 Academia Road, Section 2,

Taipei 11529, Taiwan

e-mail:yph@gate.sinica.edu.tw
The activity-regulated gene expression of transcription factors is required for neural plasticity and function in response to neuronal stimulation. T-brain-1 (TBR1), a critical neuronspecific transcription factor for forebrain development, has been recognized as a highconfidence risk gene for autism spectrum disorders. Here, we show that in addition to its role in brain development, Tbr1 responds to neuronal activation and further modulates the Grin $2 b$ expression in adult brains and mature neurons. The expression levels of Tbr 1 were investigated using both immunostaining and quantitative reverse transcription polymerase chain reaction (RT-PCR) analyses. We found that the mRNA and protein expression levels of Tbr1 are induced by excitatory synaptic transmission driven by bicuculline or glutamate treatment in cultured mature neurons. The upregulation of Tbr1 expression requires the activation of both $\alpha$-amino-3-hydroxy-5-methyl-4-isoxazole-propionic acid (AMPA) and $\mathrm{N}$-methyl-D-aspartate (NMDA) receptors. Furthermore, behavioral training triggers $\mathrm{Tbr} 1$ induction in the adult mouse brain. The elevation of Tbr1 expression is associated with Grin $2 b$ upregulation in both mature neurons and adult brains. Using Tbr1-deficient neurons, we further demonstrated that TBR 1 is required for the induction of Grin $2 b$ upon neuronal activation. Taken together with the previous studies showing that TBR1 binds the Grin $2 b$ promoter and controls expression of luciferase reporter driven by Grin $2 b$ promoter, the evidence suggests that TBR 1 directly controls Grin $2 b$ expression in mature neurons. We also found that the addition of the calcium/calmodulin-dependent protein kinase II (CaMKII) antagonist KN-93, but not the calcium-dependent phosphatase calcineurin antagonist cyclosporin A, to cultured mature neurons noticeably inhibited Tbr1 induction, indicating that neuronal activation upregulates Tbr1 expression in a CaMKII-dependent manner. In conclusion, our study suggests that Tbr1 plays an important role in adult mouse brains in response to neuronal activation to modulate the activity-regulated gene transcription required for neural plasticity.

Keywords: autism, Grin2b, immediate early gene, neuronal activation, Tbr1

\section{INTRODUCTION}

Neuronal activation regulates the activity of transcription factors to modulate the gene expression required for the formation of mature synapses and neural circuits and development of cognitive function (Parkes and Westbrook, 2011). Abnormalities in activity-regulated transcriptional pathways have been implicated in neurodevelopmental disorders (Pfeiffer et al., 2010; King et al., 2013), especially in autism spectrum disorders (ASDs), which are characterized by deficits in social interaction and communication, cognitive inflexibility, repetitive behaviors, and intellectual disability. Recent genetic studies have found recurrent mutations of T-brain-1 (TBR1), encoding a brain-specific T-box transcription factor (Bulfone et al., 1995), in ASD patients and identified Tbr1 as a causative gene in ASDs (Neale et al., 2012; O'Roak et al., 2012a; Huang et al., 2014).

Tbr1 is specifically expressed in the olfactory bulb, cerebral cortex, hippocampus, and amygdala (Bulfone et al., 1995, 1998;
Medina et al., 2004; Remedios et al., 2007). Its peak expression is observed during the embryonic stage, and the expression gradually decreases after birth (Bulfone et al., 1995). TBR1 protein is expressed at low, but significant, levels in the adult forebrain (Hsueh etal., 2000). At the embryonic stage, Tbr1, which is abundantly expressed in post-mitotic projection neurons, controls the axonal connections between the cerebral cortex and thalamus and the formation of the corticospinal tract (Hevner et al., 2001). Studies using knockout mice demonstrated that Tbr1 plays important roles in the maintenance of neuronal projections in the olfactory bulb (Bulfone etal., 1998), layer and regional identification of the neocortex (Hevner et al., 2001; Bedogni et al., 2010), and migration of the amygdala (Remedios et al., 2007). Moreover, we recently showed that TBR1 modulates expression of Ntng1, Cdhs, and Cntn2 and regulates the axonal outgrowth of amygdalar neurons, which are critical for the inter- and intra-amygdalar connections (Huang et al., 2014). 
All of these studies indicate that Tbr1 is significantly involved in brain development.

Our previous studies showed that TBR1 interacts with CASK (calcium/calmodulin-dependent serine protein kinase; Hsueh et al., 2000; Hsueh, 2009). Mutations in the CASK gene result in X-linked mental retardation (Najm et al., 2008; Tarpey et al., 2009; Moog et al., 2011). The CASK-TBR1 protein complex regulates the expression of glutamate receptor, ionotropic, N-methyl-Daspartate $2 B$ (Grin $2 b$, also known as Nmdar2b; Wang et al., 2004a,b), which is critical for learning and memory and involved in autism and schizophrenia (Kristiansen et al., 2010; O'Roak et al., 2012b). Recently, we demonstrated that Tbr1-deficient mice exhibit autistic-like behaviors (Huang et al., 2014). Upon behavioral stimulation, the induction of Grin $2 b$ expression was impaired in Tbr1 heterozygous mice, indicating that Tbr1 is likely required for the induction of Grin $2 b$ upon neuronal activation. Thus, in addition to regulating neuronal development, Tbr1 likely responds to neuronal activation and controls Grin $2 b$ expression in adult brains.

In literatures, neuronal activation-induced immediate early gene (IEG) responses have been demonstrated to be relevant to dysfunction of glutamatergic pathways and psychological stress. First of all, stress-induced dysregulation in glutamate transmission contributes to development of schizophrenia and other mood disorders (de Kloet et al., 2005; Popoli et al., 2012; Weickert et al., 2013), indicating glutamatergic system has a strong impact on psychiatric disorders. Moreover, acute stress elevates the glucocorticoid levels and activates glucocorticoid receptor, a ligand-inducible nuclear transcription factor, to induce an increase of presynaptic SNARE complexes and thus further enhance glutamate release (Popoli etal., 2012). At the postsynaptic sites, acute stressful conditions induce expression of a series of IEGs, including early growth response 1 (Egrl) and activity-regulated cytoskeletal-associated protein $(A r c)$, and change $\alpha$-amino-3-hydroxy-5-methyl-4-isoxazole-propionic acid (AMPA)/N-methyl-D-aspartate (NMDA) receptor-mediated glutamatergic transmission. It then impacts on neuronal activationdependent synaptic plasticity (Revest et al., 2005; Fumagalli et al., 2011; Benekareddy etal., 2013). Besides, both acute behavioral stress in live animals and corticosterone treatment in brain slices increase the synaptic expressions and function of NMDA and AMPA receptors through the upregulation of serum- and glucocorticoid-inducible kinase (SGK), another IEG, and activation of RAB4, a regulator for endocytic recycling of receptors (Yuen et al., 2011). All of these studies support that psychological stress influences the activity-mediated glutamatergic transmission and activates or regulates the downstream genes via IEGs. Since TbrI has been shown to directly regulate the expression of Grin $2 b$ and Tbr1 plays roles in psychiatric disorders, Tbr1 is a likely candidate that senses the neuronal stimulations and regulates glutamatergic pathways.

In this report, we demonstrate that neuronal activation in mature cultured neurons and behavioral stimulation in adult mice indeed upregulate the expression of Tbr1 and that the elevation of TBR1 can further induce Grin $2 b$ expression. We also found that activity-dependent Tbr1 expression is regulated via the NMDA receptor and calcium/calmodulin-dependent protein kinase II (CaMKII)-mediated signaling, suggesting a positive feedback loop to control neuronal activity via TBR1 and NMDAR. Our study provides evidence that Tbrl also plays a role in the response of mature neurons to neuronal activation.

\section{MATERIALS AND METHODS ANIMALS}

Tbr1 $1^{+/}$mice were originally provided by Dr. Robert Hevner (Department of Neurological Surgery, University of Washington, Seattle) with the permission of Dr. John Rubenstein (Department of Psychiatry, University of California at San Francisco; Hevner et al., 2001). The mice were maintained in a specific pathogenfree temperature- and humidity-controlled facility at the Institute of Molecular Biology, Academia Sinica, and backcrossed into a C57BL/6 background for over 20 generations. Wild-type C57BL/6 mice were purchased from the National Laboratory Animal Center, Taiwan. All animal experiments were conducted with the approval of the Academia Sinica Institutional Animal Care and Utilization Committee, and in strict accordance with its guidelines and those of the Council of Agriculture Guidebook for the Care and Use of Laboratory Animals.

\section{ANTIBODIES AND CHEMICALS}

The rabbit polyclonal TBR1 antibody (TBRC) has been described previously (Hsueh etal., 2000). The mouse monoclonal MAP2 antibody was purchased from Sigma-Aldrich. The Alexa Fluor ${ }^{\circledR}$ 488- and Alexa Fluor ${ }^{\circledR} 555$-conjugated secondary antibodies were purchased from Invitrogen. The following drugs were used: glutamate was purchased from Invitrogen; tetrodotoxin (TTX), bicuculline, 2,3-dihydroxy-6-nitro-7-sulfamoyl-benzo(f)quinoxaline (NBQX) and NMDA were obtained from Tocris Bioscience; DL-2amino-5-phosphonovaleric acid (AP5), cyclosporin A (CsA) and KN-93 were purchased from Sigma-Aldrich.

\section{PRIMARY CULTURED NEURONS}

The hippocampal and amygdalar neurons from postnatal day 1 (P1) mouse pups were dissociated with papain (Sigma) and grown in neurobasal medium (Invitrogen) supplemented with 2\% B27 supplement (Invitrogen), $0.5 \mathrm{mM}$ glutamine, and $12.5 \mu \mathrm{M}$ glutamate. The amygdala was dissected as described in a previous study (Lesscher et al., 2008). The cortices from embryonic day 17.5 mice were trypsinized, dissociated, and cultured in neurobasal medium with $2 \%$ B27 supplement and $0.5 \mathrm{mM}$ glutamine. For immunofluorescence staining, 350,000 neurons per well were plated in 12-well plates with poly-L-lysine-coated coverslips. For quantitative polymerase chain reaction (PCR) analysis, neurons were plated at a density of 1,000,000 cells/well in poly-L-lysinecoated 6-well plates. Under these conditions, the cultures were treated with drugs and subjected to subsequent experiments after 21 days in vitro (DIV).

\section{QUANTITATIVE PCR}

The RNA from cultured neurons and different brain regions of adult mice was purified as described (Huang etal., 2014). The extracted RNA was then subjected to complementary DNA (cDNA) synthesis using the Transcriptor First Strand cDNA Synthesis Kit (Roche) according to the 
manufacturers' instructions. The LightCycler 480 Probes Master kit (Roche) was used for the quantitative-PCR assay. The primer sets for Tbr1 were 5'-CAAGGGAGCATCAAACAACA$3^{\prime}$ and $5^{\prime}$-GTCCTCTGTGCCATCCTCAT- $3^{\prime}$. The primer sets for Grin $2 b$ were $5^{\prime}$-GGGTTACAACCGGTGCCTA-3' and $5^{\prime}$ CTTTGCCGATGGTGAAAGAT- $3^{\prime}$. The primer sets for c-Fos were $5^{\prime}$-GGGACAGCCTTTCCTACTACC- $3^{\prime}$ and $5^{\prime}$ - AGATCTGCGCA AAAGTCCTG-3'.

\section{IMMUNOFLUORESCENCE STAINING}

Primary cultured neurons were fixed with 4\% paraformaldehyde and $4 \%$ sucrose in phosphate buffered saline (PBS) at room temperature (RT) for $10 \mathrm{~min}$, permeabilized with $0.1 \%$ TritonX-100 in PBS for $10 \mathrm{~min}$, and blocked with $2 \%$ bovine serum albumin (BSA) and 3\% horse serum (HS) in PBS for $2 \mathrm{~h}$. After blocking, the neurons were incubated with anti-TBR1 antibody $(4 \mu \mathrm{g} / \mathrm{ml})$ and anti-MAP2 antibody (1:500) in PBS containing $2 \%$ BSA and $3 \% \mathrm{HS}$ overnight at $4^{\circ} \mathrm{C}$. After washing, the cells were incubated with the corresponding secondary antibodies conjugated with Alexa Fluor ${ }^{\circledR} 488$ and Alexa Fluor ${ }^{\circledR} 555$ at RT for 2 h, followed by mounting in Vectashield mounting medium (Vector Laboratories). Counter stain with 4',6-diamidino-2-phenylindole dihydrochloride (DAPI) was performed to label nuclei of neurons. The images were captured with a confocal microscope (LSM 700; Carl Zeiss) and then analyzed with the MetaMorph analysis software (MetaMorph) to quantify the TBR1 fluorescence intensity. The single-plane image was opened and the multi-wavelength cell scoring module was used to score the TBR1 fluorescence intensity of neurons. The regions of nuclei were defined by the signals of DAPI. The average intensity of nuclear TBR1 was determined to indicate the mean fluorescence intensity of TBR1. For each experiment, about thirty neurons were collected in each treatment. At least three independent experiments were carried out. The statistical analysis was performed using the pooled data from repeated experiments.

\section{CONDITIONED TASTE AVERSION}

The behavioral paradigm was as previously described (Huang et al., 2014). Briefly, water-deprived mice at 10-16 weeks of age were trained to receive their daily water for $15 \mathrm{~min}$ in the experimental cages during the pre-training period. On training day (D0), mice were offered a sucrose solution as a new pleasant taste for $15 \mathrm{~min}$ and were subsequently intraperitoneally injected with lithium chloride ( $\mathrm{LiCl} ; 0.15 \mathrm{M}, 20 \mu \mathrm{l} / \mathrm{g}$ of body weight) to induce aversive responses or with sodium chloride $(\mathrm{NaCl})$ as a control. Two or twenty-four hours after injection, mice were sacrificed by cervical dislocation. Different brain areas were then sampled for the subsequent quantitative PCR analysis.

\section{STATISTICAL ANALYSIS}

Data are presented as the mean \pm SEM. The statistical analysis was performed using one-way ANOVA with a post hoc Dunnett test (Figures 1, 3, 4C-E, and 6) and an unpaired $t$-test (Figure 2) in GraphPad Prism or a two-way ANOVA with a post hoc Bonferroni test (Figures 4B and 5) via the SigmaStat software version 3.5 (Copyright $^{\odot} 2006$ Systat Software, Inc., Germany). A $P$ value $<0.05$ was considered significant.

\section{RESULTS}

\section{THE TBR1 PROTEIN LEVELS ARE REGULATED BY NEURONAL ACTIVITY IN CULTURED NEURONS}

Upon behavioral stimulation, most TBR1-positive projection neurons in the amygdalae of adult brains express c-FOS (Huang et al., 2014), a marker for neuronal activity, which suggests the involvement of TBR1-positive neurons in behavioral responses. To examine whether Tbr1 is regulated by or participates in neuronal activation, we first examined the expression of TBR1 in mature amygdalar neurons at 21 DIV using double immunofluorescence staining with TBR1 and the neuronal marker MAP2. The cultures were incubated with the sodium channel blocker TTX $(1 \mu \mathrm{m})$ or with the ionotropic $\mathrm{GABA}_{\mathrm{A}}$-antagonist bicuculline $(40 \mu \mathrm{m})$ for $6 \mathrm{~h}$ to reduce or activate neuronal activity, respectively. Consistent with the previous studies and the role of TBR1 as a transcription factor (Hsueh et al., 2000), we found that TBR1 was mainly located in cell nuclei in the absence of special treatment, though the levels were low (Figure 1A). Interestingly, we found that incubation with bicuculline but not TTX increased the protein expression levels of TBR1 in mature amygdalar neurons (Figure 1A). Because TBR1 is also expressed in the cerebral cortex and hippocampus of the adult brain (Hong and Hsueh, 2007), mature cortical and hippocampal neurons were also used to investigate the induction of TBR1 after neuronal activation. Similarly, bicuculline treatment increased the TBR1 protein levels in the cortical and hippocampal neurons (Figures 1B,C), though the degree of TBR1 induction in hippocampal neurons was much lower than those in amygdalar or cortical neurons (Figure 1). These data indicate that the protein levels of TBR1 are upregulated by neuronal activation.

\section{NMDAR ACTIVATION STIMULATES TBR1 EXPRESSION}

Because bicuculline drives neuronal excitability by blocking the activity of inhibitory neurons and because Tbr1 is expressed in excitatory projection neurons (Hevner et al., 2001; Huang et al., 2014), bicuculline likely reduces the inhibitory effect of inhibitory neurons and indirectly increases the expression of Tbr1 in projection neurons. We then examined whether the direct activation of projection neurons by glutamate stimulation also increases TBR1 expression. Similar to bicuculline treatment, we found that TBR1 expression was induced in mature amygdalar neurons after glutamate stimulation (Figure 2A). Among the various glutamate receptors, NMDA receptors are the major glutamate receptors to induce calcium influx and play important roles in the regulation of long-term potentiation, synaptic plasticity, learning and memory. We then investigated whether the induction of TBR1 expression by glutamate depended on the NMDA receptor. NMDA treatment also effectively induced TBR1 upregulation in amygdalar, cortical, and hippocampal neurons (Figures 2B-G). Together, these results support that TBR1 expression undergoes NMDA receptor-dependent regulation.

\section{Tbr1 UPREGULATION ASSOCIATES WITH Grin2b INDUCTION IN NEURONAL CULTURES}

In addition to the protein levels, we performed quantitative RTPCR analysis to examine the change of the Tbr1 mRNA levels upon neuronal activation. Immediately after treatment with TTX or bicuculline for $6 \mathrm{~h}$, cultured amygdalar neurons were either 


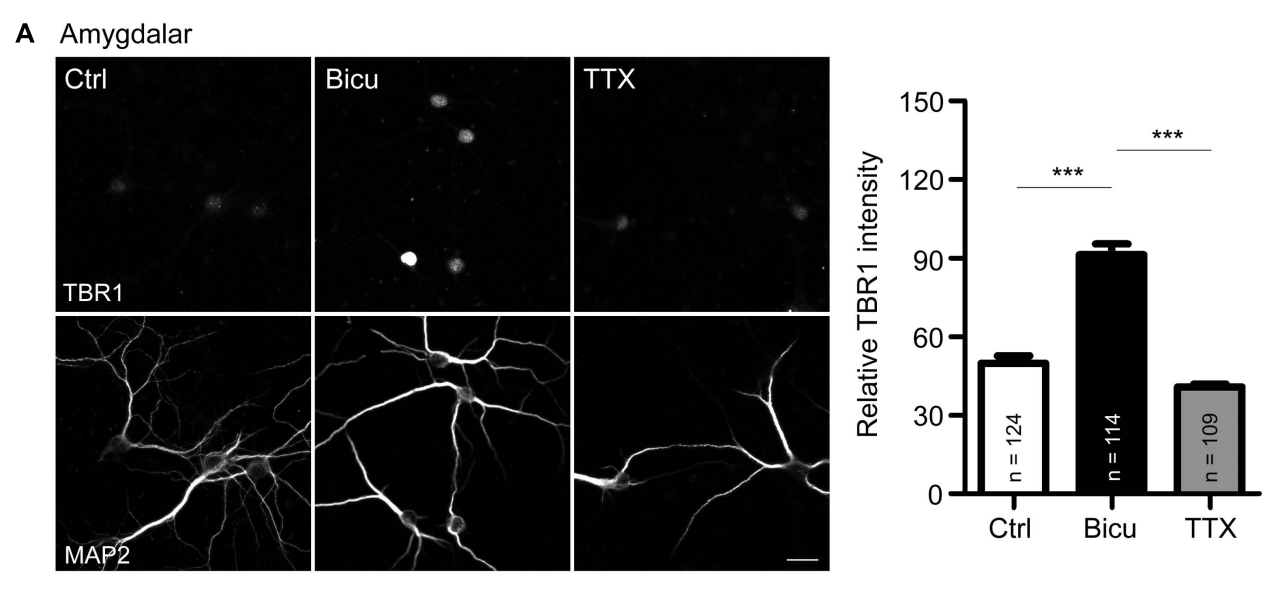

B Cortical
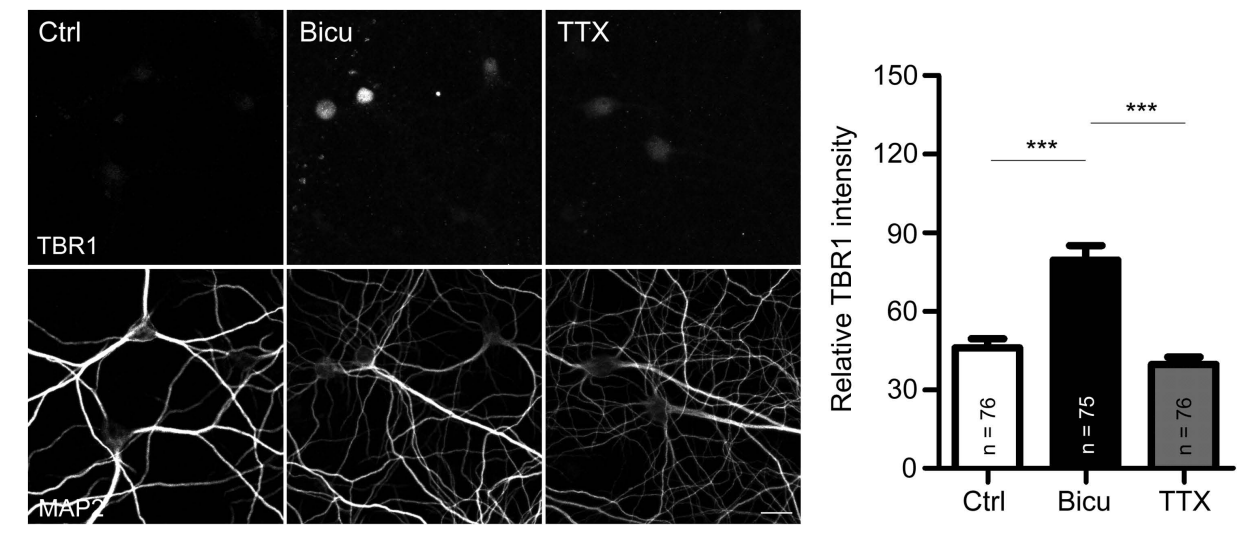

C Hippocampal
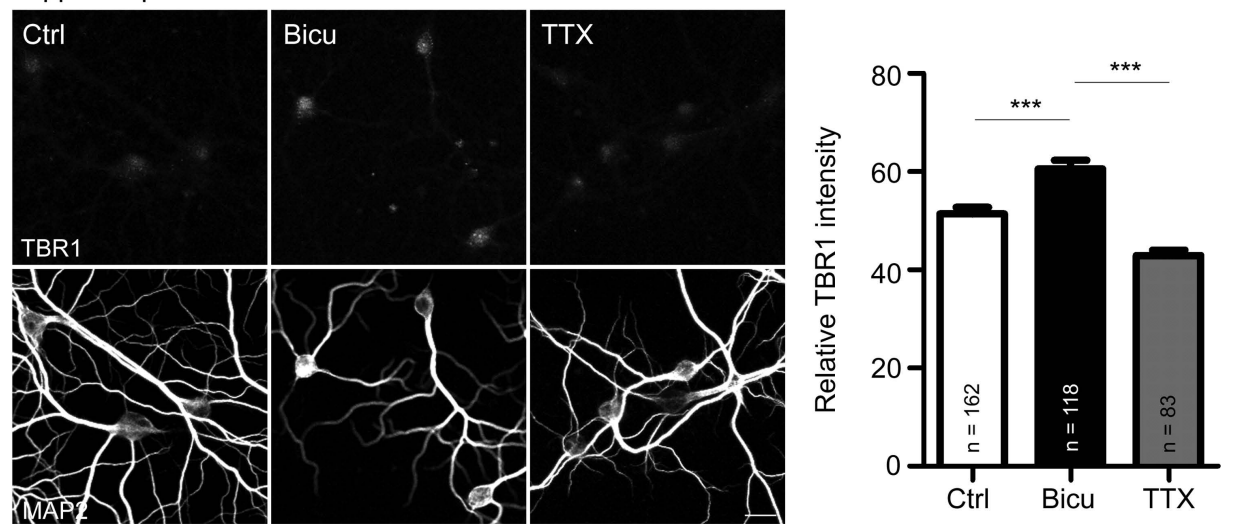

FIGURE 1 |T-brain-1 proteins are induced by neuronal activation in cultured neurons. (A-C) Double immunostaining with TBR1 and MAP2 antibodies. Primary amygdalar (A), cortical (B), and hippocampal (C) neurons were incubated with TTX $(1 \mu \mathrm{M})$ or bicuculline (Bicu, $40 \mu \mathrm{M})$ for $6 \mathrm{~h}$ at 21 DIV. Neurons were then fixed for immunostaining.
Scale bars: $20 \mu \mathrm{m}$. The bar graphs in right panels of (A-C) show the mean fluorescence intensity of TBR1 quantified by MetaMorph software. All data are presented as the mean + SEM. The number of neurons (n) analyzed for each experiment is indicated in the figure. ***P $<0.001$. harvested for RNA extraction or washed and incubated in normal culture medium for 12 more hours. We found that while Tbr1 expression was not affected by TTX treatment, the Tbr1 mRNA levels were highly elevated immediately after bicuculline stimulation (labeled as " 0 " hour after treatment in the figure). Interestingly, we noticed that Tbrl expression was significantly decreased to a level comparable to that of the vehicle control at $12 \mathrm{~h}$ after bicuculline treatment. Similarly, the expression levels of Tbr1 from both cortical and hippocampal neurons were upregulated immediately after bicuculline treatment and decreased $12 \mathrm{~h}$ after stimulation (Figures 3B,C), suggesting a transient induction of Tbr1 expression after neuronal activation. 


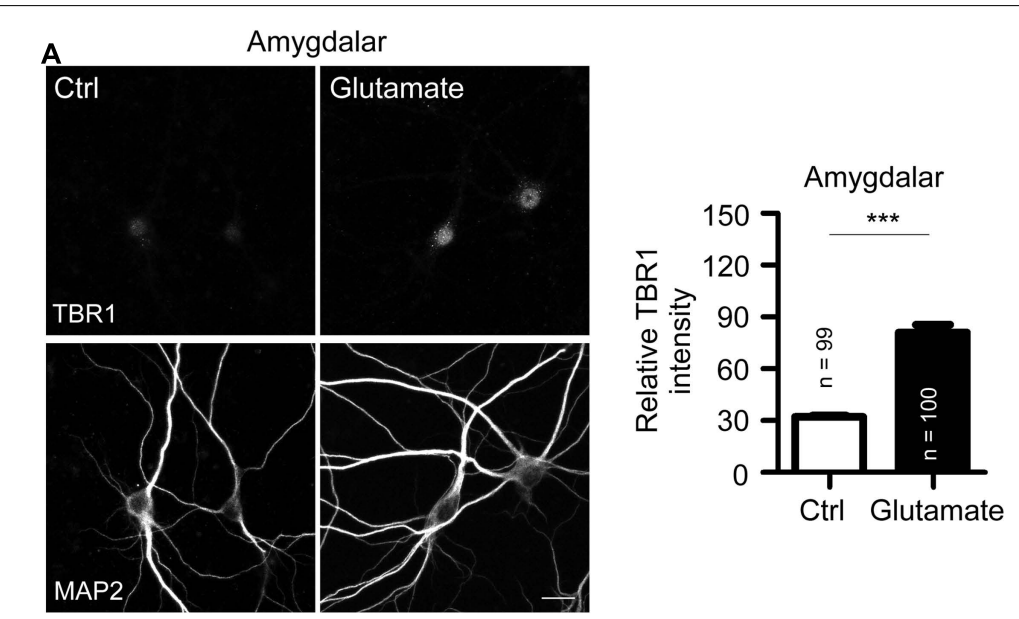

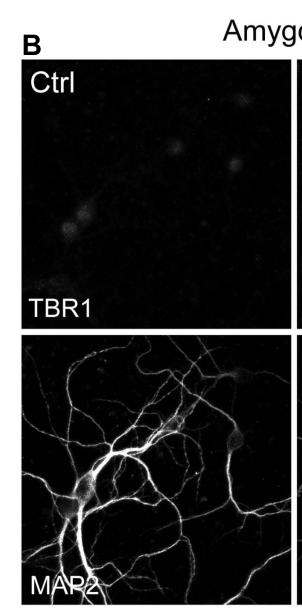

E

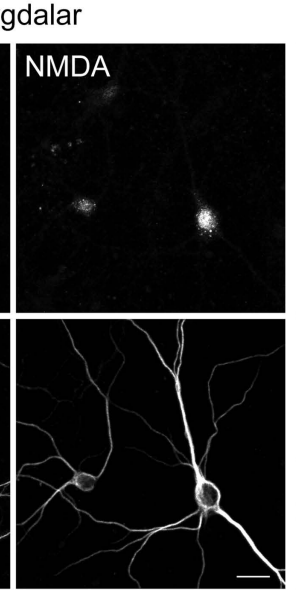

Amygdalar

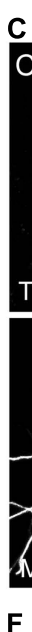

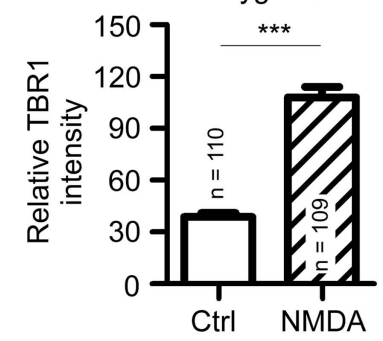

Cortical

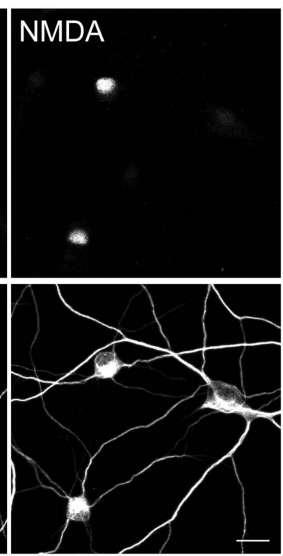

Cortical

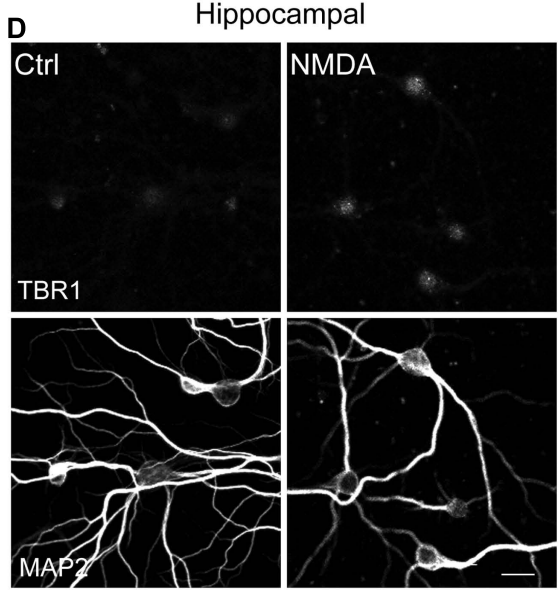

G
Hippocampal

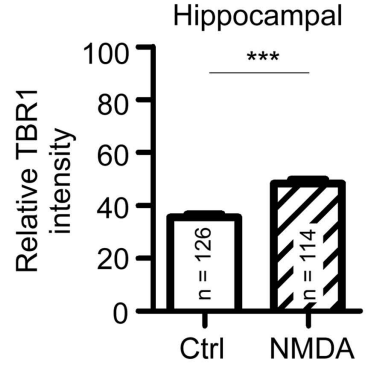

FIGURE 2 | $\boldsymbol{N}$-methyl-D-aspartate receptor activation induces TBR1 expression in cultured neurons. (A) Mature amygdalar neurons at 21 DIV were treated with glutamate $(50 \mu \mathrm{M})$ for $10 \mathrm{~min}$ and transferred to normal culture medium for 2 more hours. Neurons were then fixed and immunostained with TBR1 and MAP2 antibodies. Quantitative data show the relative intensity of TBR1 fluorescence. (B-D) The mature amygdalar (B), cortical (C), and hippocampal (D) neurons were incubated with NMDA $(10 \mu \mathrm{M})$ for $6 \mathrm{~h}$. After staining with TBR1 and MAP2 antibodies, the means of TBR1 fluorescence intensities are shown in (E-G). Scale bars: $20 \mu \mathrm{m}$. All data represent the mean + SEM. The number of neurons ( $n$ ) for each experiment is indicated in the panels. ${ }^{* *} P<0.001$.
To further confirm if NMDA receptor signaling is also involved in the induction of Tbr1 mRNA expression, we also stimulated cultured amygdalar, cortical, and hippocampal neurons with NMDA for quantitative RT-PCR analysis. We found that the mRNA levels of Tbrl showed a noticeable increase immediately after NMDA treatment for $6 \mathrm{~h}$ and declined to basal levels $12 \mathrm{~h}$ after NMDA washout (Figures 3D-F). Together with the immunostaining analysis, these data support that both the mRNA and protein levels of Tbr1 are upregulated in an activity-dependent manner via the NMDA receptor.

Because TBR1 was shown to directly regulate the expression of Grin2b (Wang etal., 2004b), one of the NMDAR subunits implicated in proper neuronal activity, and because the GRIN2B expression levels were upregulated upon behavioral stimulation (Huang etal., 2014), we then assessed whether the activitydependent upregulation of Tbr1 expression is relevant to the 


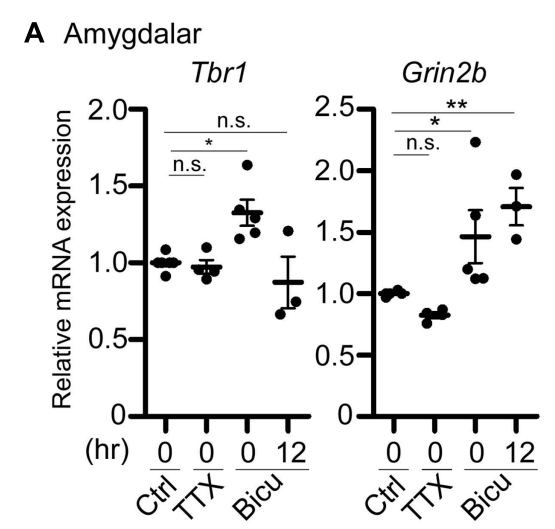

D Amygdalar

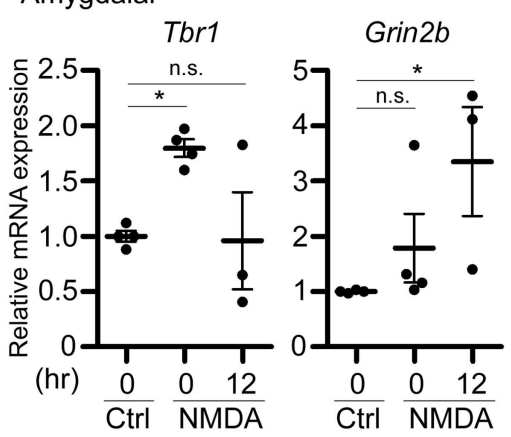

B Cortical
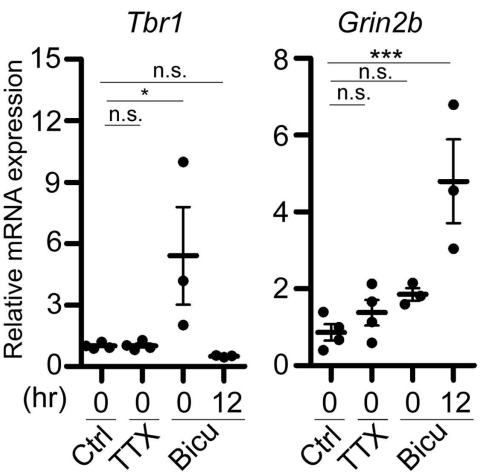

E Cortical
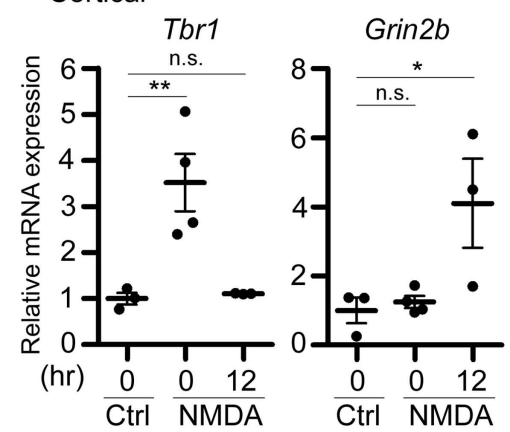

C Hippocampal

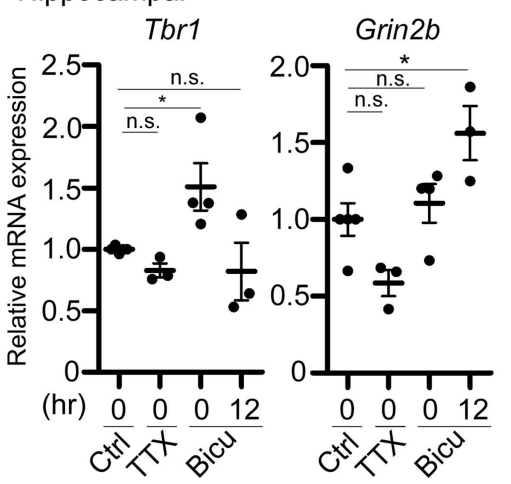

F Hippocampal

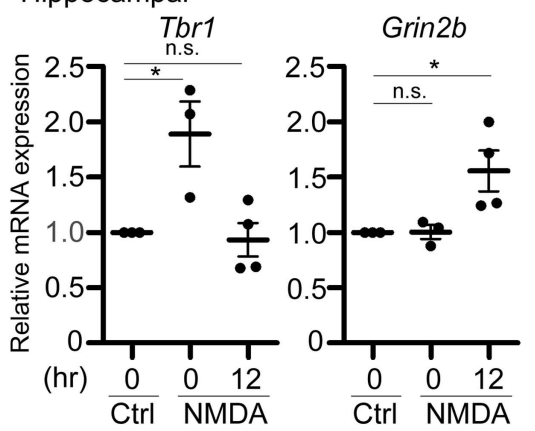

FIGURE 3 | Tbr1 upregulation correlates with Grin2b induction in cultured neurons. Quantitative-PCR analyses were performed to examine the expression of Tbr1 and Grin2b upon (A-C) TTX and bicuculline (Bicu) treatment and (D-F) NMDAR activation. Cultured amygdalar $(\mathbf{A}, \mathbf{D})$, cortical $(\mathbf{B}, \mathbf{E})$, and hippocampal $(\mathbf{C}, \mathbf{F})$ neurons were incubated with TTX $(1 \mu \mathrm{M})$, bicuculline $(40 \mu \mathrm{M})$, NMDA $(10 \mu \mathrm{M})$, or vehicle (Ctrl) for $6 \mathrm{~h}$. Immediately $(0 \mathrm{~h})$ or 12 more hours (12 h) after treatment, neurons were harvested for quantitative-PCR using Cyp as an internal control to quantify the relative mRNA levels of Tbr1 and Grin2b at 21 DIV. The experiments were performed independently at least three times. Data are presented as the mean \pm SEM. ${ }^{*} P<0.05$; ${ }^{*} P<0.001 ; * * *<0.001$; n.s., not significant. induction of Grin $2 b$ during neuronal activation. Therefore, the RNA expression level of Grin $2 b$ was also examined. We found that the Grin $2 b$ expression levels tended to be increased immediately after treatment with bicuculline or NMDA for $6 \mathrm{~h}$, although only the bicuculline treatment of amygdalar neurons resulted in significant differences from vehicle-treated neurons (Figure 3). In all amygdalar, cortical and hippocampal neurons, the Grin $2 b$ mRNA levels were noticeably upregulated $12 \mathrm{~h}$ after bicuculline or NMDA treatment (Figure 3), suggesting a time delay in the upregulation of Grin $2 b$ expression after neuronal activation. These data indicate that neuronal activation first induces Tbr1 upregulation and then increases Grin $2 b$ expression.

BEHAVIORAL TRAINING INDUCES Tbr1 UPREGULATION IN ADULT MICE We then employed behavioral stimulation to investigate whether Tbr1 responds to neuronal activity and regulates Grin $2 b$ expression in vivo. The conditioned taste aversion (CTA) test, an amygdala-dependent learning and memory test, was chosen for behavioral stimulation. In CTA, mice will learn to correlate a novel food (sucrose) with aversive responses induced by $\mathrm{LiCl}$ injection (Figure 4A). An injection of $\mathrm{NaCl}$ was used as a control. Consistent with a previous observation (Huang et al.,
2014), the amounts of sucrose solution drunk on the training day (D0) were higher than the amounts of water drunk during pre-training (D-1), suggesting that all mice behaved normally to prefer to drink sucrose (Figure 4B). Two or $24 \mathrm{~h}$ after training, animals were sacrificed to examine the expression of Tbr1 and Grin $2 b$ mRNAs using quantitative RT-PCR. In the lateral amygdala, the expression levels of Tbr1 or Grin $2 b$ were highly upregulated $2 \mathrm{~h}$ but significantly decreased $24 \mathrm{~h}$ after CTA training (Figures 4C,D, the groups of 2 and $24 \mathrm{~h}$ after $\mathrm{LiCl}$ injection). Because the amygdala has strong reciprocal interactions with the ventral hippocampus and insular cortex to modulate behavioral responses (Piette et al., 2012; Felix-Ortiz and Tye, 2014), we then examined whether CTA training also increases the expression levels of Tbr1 and Grin $2 b$ in the ventral hippocampus and insular cortex. The induction of Tbr1 and Grin $2 b$ were observed in these two brain regions (Figures 4C,D). These in vivo data support that both Tbrl and Grin $2 b$ were upregulated in the brain in response to behavioral stimulation.

Because $c$-Fos has been shown to be an IEG that is upregulated after behavioral training (Montag-Sallaz et al., 1999), we also included $c$-Fos as a positive control in the quantitative PCR assay. Similar to Tbr1 mRNA, we found that the $c$-Fos expression levels 
A

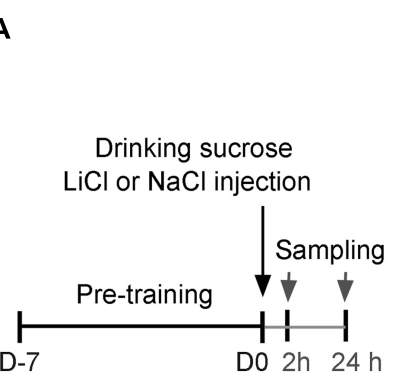

D

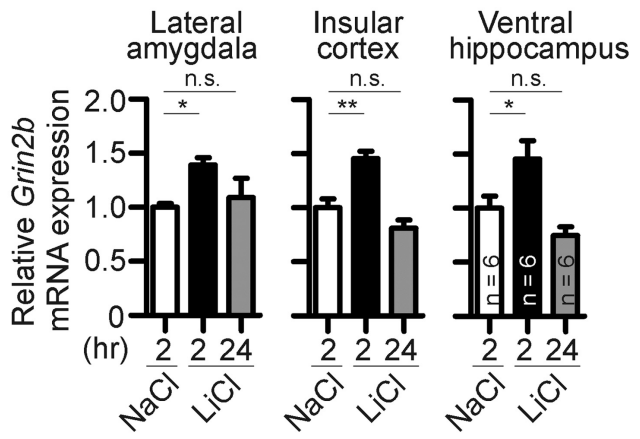

FIGURE 4 | Behavioral stimulation results in upregulation of Tbr1 and Grin2b in adult brains. (A) A simple flowchart of CTA test. The tissues were sampled 2 and $24 \mathrm{~h}$ after injection. (B) The amounts of water drunk during pre-training (D-1) and sucrose drunk on the CTA training day (D0). (C-E) Quantitative-PCR analyses to examine the expression of Tbr1, Grin2b, and c-Fos upon behavioral training. Two hours after $\mathrm{NaCl}$ or $\mathrm{LiCl}$ injection and
C
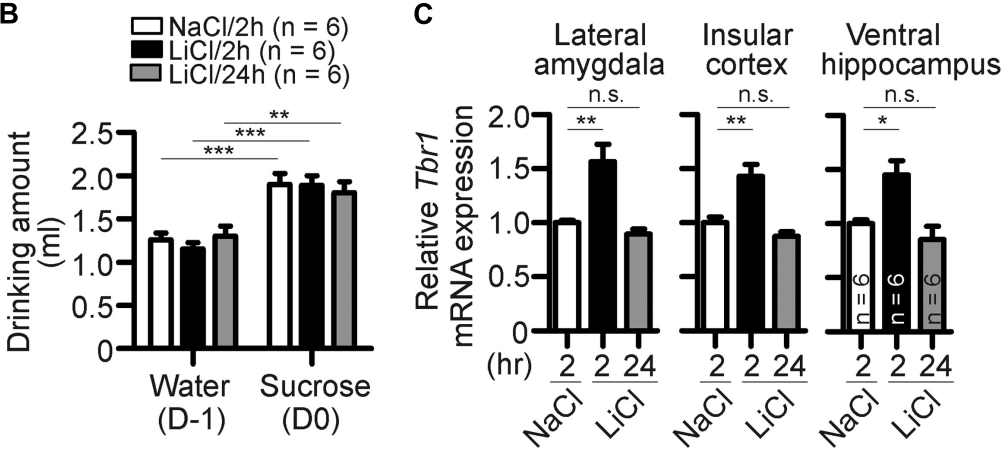

(D0)

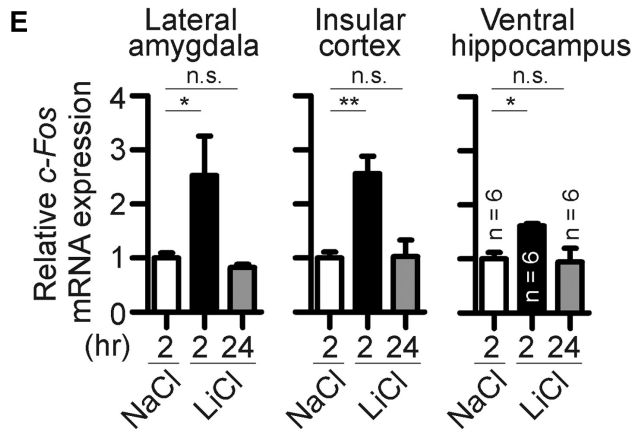

$24 \mathrm{~h}$ after $\mathrm{LiCl}$ injection, the lateral amygdala, insular cortex and ventral hippocampus were collected for quantitative-PCR using Cyp as an internal control to detect the relative mRNA levels of Tbr1 (C), Grin2b (D), and c-Fos (E) in adult mice. Six animals were used for each experiment. All data represent the mean + SEM. ${ }^{*} P<0.05$; ${ }^{* *} P<0.001$; ${ }^{* *} P<0.001$; n.s., not significant.
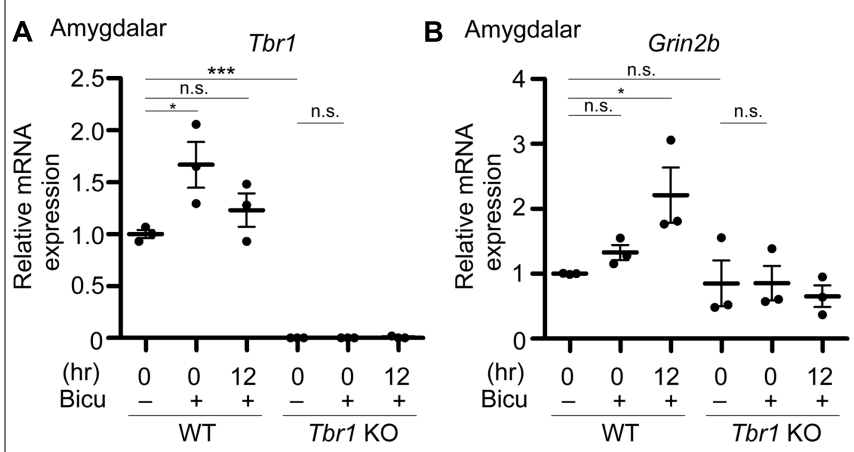

FIGURE 5 | Grin2b induction upon neuronal activation requires Tbr1 expression in neuronal cultures. Bicuculline (Bicu, $40 \mu \mathrm{M})$ was added to the WT and Tbr $1 \mathrm{KO}$ amygdalar cultures at 21 DIV for $6 \mathrm{~h}$. Quantitative-PCR analysis was conducted to measure the relative mRNA levels of Tbr1 (A) and Grin $2 b(\mathbf{B})$ immediately $(0 \mathrm{~h})$ and $12 \mathrm{~h}$ after bicuculline stimulation. The Cyp expression level was used as an internal control. Tbr1 $\mathrm{KO}$ amygdalar neurons did not respond to bicuculline in terms of Grin $2 b$ induction. Experiments were repeated three independent times. Data represent the mean \pm SEM. ${ }^{*} P<0.05 ;{ }^{*} P<0.001$; n.s., not significant.

in the lateral amygdala, insular cortex, and ventral hippocampus were upregulated at $2 \mathrm{~h}$ but returned to a level comparable to that of the control $24 \mathrm{~h}$ after CTA training (Figure 4E). The

c-Fos expression pattern confirmed the neuronal activation upon behavioral stimulation in our experiment.

\section{TBR1 IS REOUIRED FOR THE INDUCTION OF Grin2b UPON NEURONAL ACTIVATION}

To directly investigate whether an increase in TBR1 expression in cultured neurons is essential to Grin $2 b$ upregulation, Tbr1 knockout $(\mathrm{KO})$ amygdalar neurons were cultured, and their response to bicuculline was investigated. Similar to the aforementioned data, the Tbr1 mRNA levels showed a noticeable increase in WT neurons immediately after bicuculline stimulation (Figure 5A). Tbr1 mRNA was not detected in Tbr1 KO neurons, supporting the specificity of our quantitative RT-PCR (Figure 5A). More importantly, we found that the Grin $2 b$ mRNA expression was no longer increased $12 \mathrm{~h}$ after bicuculline treatment in Tbr1 KO neurons (Figure 5B). These results support that TBR1 is required for the induction of Grin $2 b$ expression upon neuronal activation.

\section{CaMKII IS REQUIRED FOR THE Tbr1 INDUCTION}

The above results have demonstrated the upregulation of Tbr1 expression upon neuronal activation in vitro and in vivo. We next investigated the possible mechanisms by which neuronal activity induces Tbr1. Upon the excitatory synaptic transmission triggered by bicuculline or glutamate treatment, the depolarization of the plasma membrane via AMPA glutamate receptors 


\section{A Cortical}

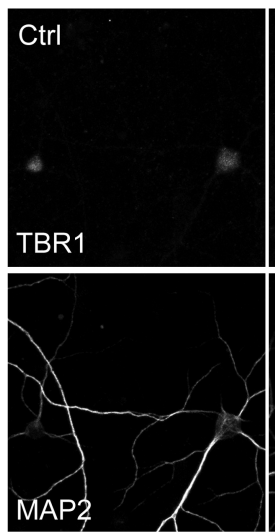

B

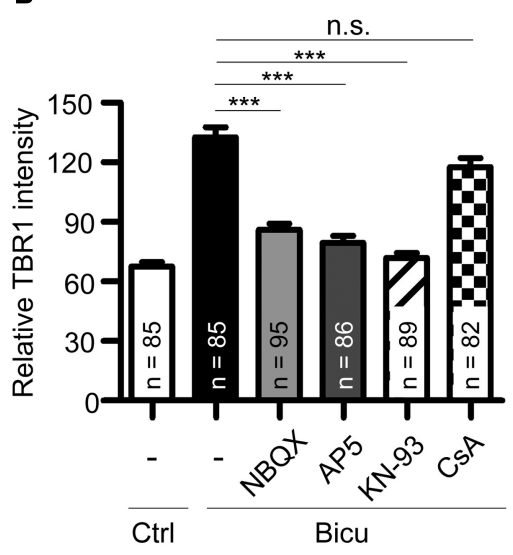

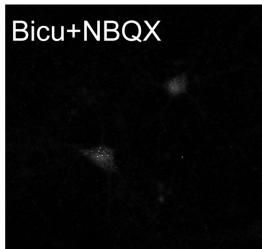

Bicu+AP5
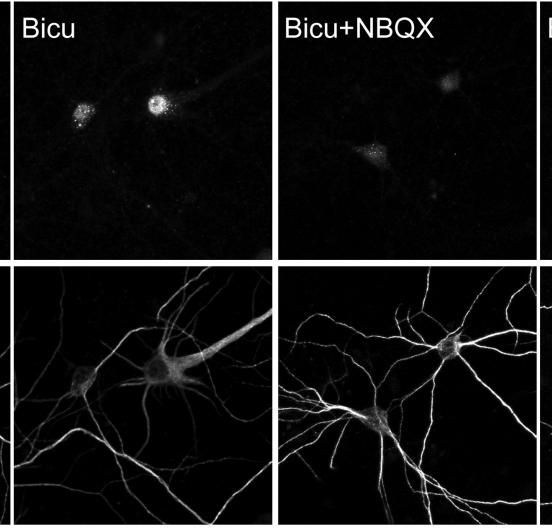

C Cortical

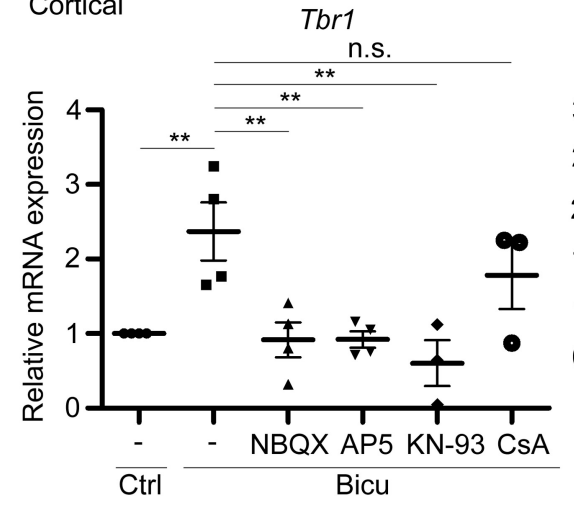

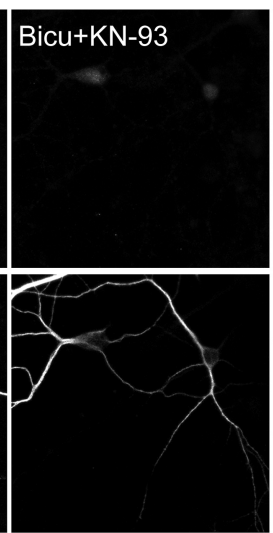
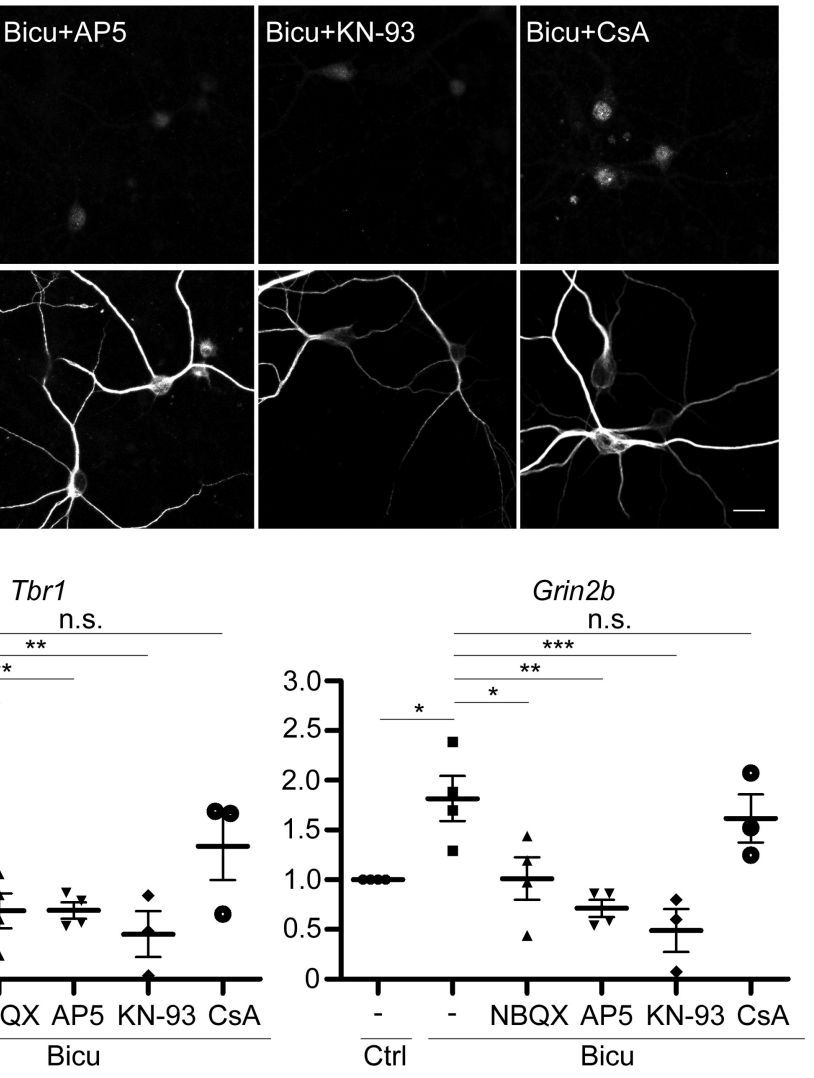

FIGURE 6 | T-brain-1 upregulation requires activation of CaMKII in neuronal cultures. Cultured cortical neurons of WT mice were pretreated with APV $(100 \mu \mathrm{M}), \operatorname{NBQX}(100 \mu \mathrm{M}), \mathrm{KN}-93(5 \mu \mathrm{M})$, or CsA $(5 \mu \mathrm{M})$ for $30 \mathrm{~min}$ prior to bicuculline stimulation (Bicu, $40 \mu \mathrm{M})$ for $6 \mathrm{~h}$. Neurons were then fixed for immunostaining $(\mathbf{A}, \mathbf{B})$ or harvested for

quantitative-PCR (C) at 21 DIV. (A) Double immunostaining with TBR1 and MAP2 antibodies. Scale bars: $20 \mu \mathrm{m}$. The quantitative data of TBR1 fluorescence intensities are shown in (B). The number of neurons ( $n$ ) for each experiment is indicated in the figures. All data represent the mean + SEM. (C) Real-time PCR to quantify the relative mRNA levels of Tbr1 and Grin2b upon bicuculline activation. The Cyp expression level was used as an internal control. Experiments were repeated at least three independent times. All data represent the mean \pm SEM. ${ }^{*} P<0.05$; ${ }^{*} P<0.001 ;{ }^{* *} P<0.001 ;$ n.s., not significant. can trigger the opening of NMDA receptors (Soderling and Derkach, 2000). Thus, we investigated whether the AMPA receptor was required for bicuculline-induced Tbr1 upregulation. The pre-incubation of cultured cortical neurons with the AMPA receptor antagonist NBQX (100 $\mu \mathrm{M}$; for $30 \mathrm{~min})$ inhibited the induction of Tbrl expression by bicuculline at both the protein and mRNA levels (Figures 6A-C). Moreover, blocking NMDA receptor activation by incubating cells with the NMDA receptor antagonist APV $(100 \mu \mathrm{M})$ for $30 \mathrm{~min}$ prior to bicuculline application noticeably inhibited activity-dependent Tbr1 upregulation (Figures 6A-C), which is consistent with the above data indicating that the NMDA receptor is required for Tbr1 induction. These data suggest that the activations of both the AMPA and NMDA receptors contribute to $\mathrm{Tbr} 1$ induction following bicuculline treatment.

Because the NMDA receptor promotes activity-dependent gene expression by directly or indirectly activating a number of signaling molecules, such as CaMKII or calcium-dependent phosphatase calcineurin (Greer and Greenberg, 2008), we investigated whether CaMKII or calcineurin is required for Tbr1 upregulation upon bicuculline treatment. To test this possibility, the mature cortical neurons were pretreated with the CaMKII antagonist KN-93 $(5 \mu \mathrm{M})$ or calcineurin antagonist cyclosporin A (CsA; $5 \mu \mathrm{M}$ ) and then stimulated with bicuculline. Immunostaining with the TBR1 antibody indicated that pre-incubation with KN-93 could block the upregulation of TBR1 induced by bicuculline (Figures 6A,B), whereas CsA did not significantly affect TBR1 induction. In addition to blocking the protein levels, KN-93 but not CsA inhibited bicuculline-induced Tbr1 mRNA expression (Figure 6C), suggesting that neuronal activation upregulates Tbr1 expression in a CaMKII-dependent manner. Similar to the inhibition of Tbr1 upregulation, we found that the Grin $2 b$ induction in response to bicuculline activation was also blocked by inhibiting the CaMKII activity with KN-93 (Figure 6C).

Together, these results suggest that excitatory synaptic transmission driven by bicuculline treatment can activate both the 
AMPA and NMDA receptors. The signaling pathway of CaMKII underlying the activation of NMDAR is involved in neuronal activation-dependent Tbr1 upregulation. The elevation of Tbr1 expression further increases Grin $2 b$ expression (Figure 7).

\section{DISCUSSION}

\section{Tbr1 EXPRESSION AND ITS UPSTREAM REGULATION}

Tbr1 has been shown to play a critical role in brain development during the embryonic stage (Bulfone et al., 1995, 1998; Hsueh et al., 2000; Hevner et al., 2001; Medina etal., 2004; Remedios et al., 2007; Bedogni et al., 2010; Han et al., 2011). In the current report, we provide evidence that Tbrl also impacts mature neurons: neuronal activation upregulates the expression of Tbr1 to further induce Grin $2 b$ expression. Tbr 1 induction requires NMDA receptor-mediated excitatory synaptic transmission. Thus, TBR1 is involved in a positive feedback loop to upregulate NMDAR pathway.

Here, we show that the activation of CaMKII driven by calcium influx via NMDAR is required for Tbr1 expression in response to neuronal activation. However, how CaMKII signaling contributes to Tbr1 upregulation is unclear. The stimulation of NMDAR by synaptic activity activates the cyclic-AMP response element binding protein (CREB; Hardingham et al., 2002), an activitydependent transcription factor critical for learning and memory. Furthermore, ample evidence suggests that CaMKII can regulate the rapid transcription of IEGs, including $c$-Fos and brain-derived neurotrophic factor $(B d n f)$, by phosphorylating and activating CREB (Greer and Greenberg, 2008). Phosphorylation increases the interaction of CREB with the coactivator CREB-binding protein (CBP) and induces the binding to the full palindromic CRE sequence (TGACGTCA) or the half CRE site (TGACG/CGTCA) to promote expression of target genes (Zhang et al., 2005). Using

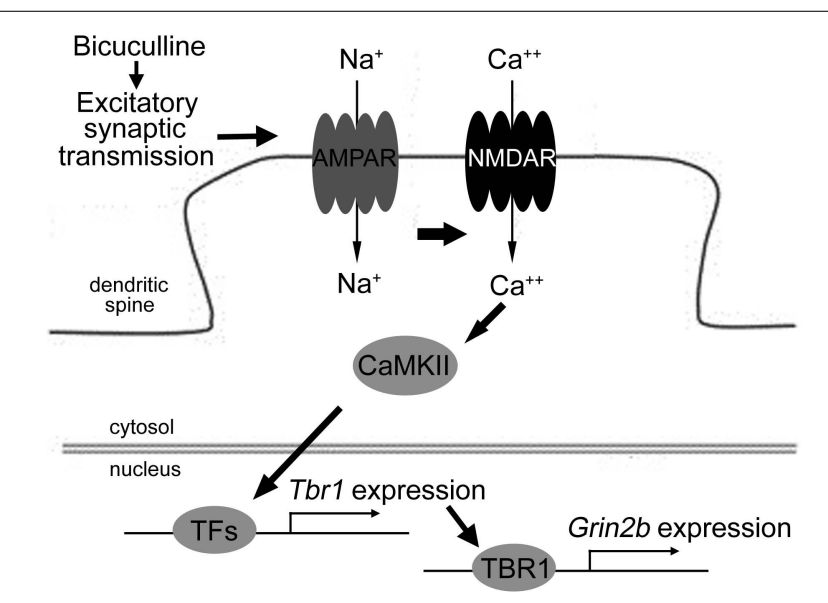

FIGURE 7 | The model of the signaling pathways elucidating Tbr1 upregulation by neuronal activation. Excitatory synaptic transmission driven by bicuculline treatment triggers the activation of the AMPA glutamate receptor. $\mathrm{Na}^{+}$influx through the AMPA receptor depolarizes the plasma membrane and then activates the NMDA receptor. The activation of CaMKII signaling via NMDAR can induce Tbr1 expression perhaps via other activity-dependent transcription factors (TFs). The elevation of the TBR1 protein levels can further upregulate the Grin $2 b$ expression following neuronal activation. the bioinformatics database (http://natural.salk.edu/CREB/), we found the several predicted CRE sites in both human and mouse Tbrl genes from the range of $5 \mathrm{~kb}$ upstream to $1 \mathrm{~kb}$ downstream of the transcription start site. For mouse Tbrl gene, the CREB binding sites are located around the nucleotide residues -4460 , $-4368,-3682,-3418,-3019,+432$, and +536 relative to the transcription initiation site. For human TBR1 gene, the half CRE sites are positioned around nucleotide residues $-4797,-862$, and +478 relative to transcription start site. These bioinformative analyses also favor that CREB is likely a candidate to induce Tbr1 expression, although further experiments such as electrophoretic mobility shift assay and luciferase reporter assay are needed to confirm this speculation.

In addition to CaMKII, calcium influx also activates calcineurin, a calcium-activated serine phosphatase. Calcineurin plays a critical role in the synaptic plasticity through regulating the transcription factor nuclear factor of activated $\mathrm{T}$ cells (NFAT; Schwartz et al., 2009) and the activity of NMDA receptor channels (Lieberman and Mody, 1994; Victor et al., 1995). It also triggers nuclear export of histone deacetylases and thus modulates $\boldsymbol{c}$-Fos expression (Parkes and Westbrook, 2011). To test the role of calcineurin in Tbr1 expression, we have applied cyclosporine A to the cultures and found that inhibition of calcineurin with cyclosporin A (CsA) could not block the Tbr1 upregulation triggered by bicuculline, suggesting that calcineurin is not involved in neuronal activity-induced Tbr1 expression. However, in addition to regulating calcineurin, CsA has the other activities. It binds to the cyclophilins (CyPs), small intracellular regulatory proteins, to exert its immunosuppressive action. CsA is also an inhibitor for mitochondrial permeability transition by binding mitochondrial matrix-specific CyP-D and blocking its translocation to the inner membrane of mitochondria (Friberg etal., 1998). CsA treatment is also able to increase the intracellular calcium level (Kaminska et al., 2001). Failure of CsA treatment to block the Tbr1 expression indicates that none of these pathways is involved in regulation of Tbr1 expression.

Moreover, the expression of activity-dependent genes can be triggered by the activation of a number of signaling molecules, such as calcium-related signaling cascades, the Ras/MAPK pathway and Rac GTPases (Greer and Greenberg, 2008). Therefore, we cannot exclude the possibility of the involvement of other pathways in response to neuronal activation to induce Tbr1 expression. Conversely, the activity-dependent epigenetic modification of the chromatin structure has been implicated in the regulation of the expression of IEGs in response to neuronal activation (Parkes and Westbrook, 2011). Tbr1 expression is regulated by AF9/MLLT3 via the methylation of histone $\mathrm{H} 3$ lysine 79 at the Tbr1 transcriptional start site (Buttner et al., 2010), indicating that epigenetic modification may be associated with Tbr1 expression. Many studies have demonstrated that epigenetic DNA methylation at $\mathrm{CpG}$ dinucleotides plays important roles in the activity-dependent neural plasticity and memory formation of mature brains (Day and Sweatt, 2010; Stevenson et al., 2011). Therefore, the ability of neuronal activation-driven epigenetic regulations, such as DNA methylation, histone acetylation, or histone phosphorylation, to control the Tbr1 expression 
in adult brain also constitutes an interesting avenue for future research.

Post-translational modification, such as protein phosphorylation, mediated by neuronal activity has been shown to regulate the transcriptional activity of transcription factors and thus play an important role in neuronal plasticity (Soderling and Derkach, 2000; Greer and Greenberg, 2008). Therefore, in addition to promoting the expression levels of Tbr1, neuronal activation may increase the transcriptional activity of TBR1 to upregulate Grin $2 b$ expression. In fact, our previous findings showed that the PKA phosphorylation of CASK, a co-activator of TBR1 (Hsueh et al., 2000), enhances the interaction between CASK and TBR1 and then promotes Grin $2 b$ expression (Huang et al., 2010). The activation of the cAMP-PKA pathway plays a critical role in learning-related synaptic plasticity and long-term memory (Kandel, 2012). Thus, the PKA phosphorylation of CASK likely indirectly increased the transcriptional activity of TBR1, which upregulated Grin $2 b$ expression and promoted memory formation in adult mice. In the future, exploring the cAMP-PKA pathway to elucidate the role of Tbr1 in mature neurons will be important.

\section{Tbr1 AND IMMEDIATE EARLY GENES}

Our study indicated that Tbr1 and c-Fos show similar transient expression patterns upon neuronal activation (Parkes and Westbrook, 2011). As discussed above, similar to $c$-Fos promoter, there are several CRE sites predicted to locate in Tbr1 promoter. We therefore suggest that Tbrl may act as an IEG to modulate neural activity-dependent gene transcription. In addition to Grin2b, the ability of TBR1 to control the expression of other neuronal activity-dependent genes is an interesting future avenue of research.

Immediate early genes are a group of genes that are expressed at low levels in quiescent cells, but are induced transiently and rapidly at the transcriptional levels in response to a variety of cellular stimulation (Sheng and Greenberg, 1990). Many IEGs, including the c-Fos family, Jun family, Zif268 (also termed Egr1), Nur77 and $c-M y c$, function as transcriptional factors. Some of genes encoding secreted proteins such as $B d n f$ and cytoskeletal proteins such as Arc comprise other important classes of IEGs (Rial Verde et al., 2006; Parkes and Westbrook, 2011). Numerous studies have demonstrated that the induction of IEGs is differentially regulated during various neural stimulation including seizure activity, stress, focal brain injury, and long-term potential, and memory formation (Hughes and Dragunow, 1995). The previous study also showed that GABAergic inhibition in primary motor cortex induces focal synchronous activation and elicits selective induction of $c$-Fos and another member of the Jun family, JunB (Berretta et al., 1997). In the report, our data also suggest the involvement of Tbr1 in regulation of GABAergic interneurons in the IEG expression. Besides, the response of IEGs also couples to morphological plasticity. The small GTPases CDC42 and RAC1 are known to be downstream of NMDAR activation in triggering actin branching/polymerization and dendritic spine enlargement (Carlisle and Kennedy, 2005; Tolias et al., 2011; Saneyoshi and Hayashi, 2012). The actin remodeling induced by activated CDC42 and/or RAC1 is able to facilitate the association of Arc mRNA with remodeled actin network at the activated synapse (Huang et al., 2007). These small GTPases also influence gene expression in the nucleus. Expression of the dominant negative mutants of $C d c 42, R a c$, or RhoA impairs the activation of transcription factor serum response factor (SRF; Hao et al., 2003), which is required for neuronal activity-induced expression of IEGs such as $c$-Fos, Arc, and Egrl (Ramanan etal., 2005). It suggests that the Rho GTPases reorganize actin cytoskeleton and thus control the SRF activity to activate IEG expression (Greer and Greenberg, 2008). Another example is the expression of pip92, an IEG critical for neuronal differentiation. RAC1 or CDC42 regulates the expression of pip92 through the activation of p21-activated kinase (PAK1; Park et al., 2007). Thus, the Rho GTPase family also contributes to the regulation of IEGs.

\section{Tbr1 UPREGULATION AND NMDAR ACTIVITY IN AUTISM}

In our analyses, Tbr1 expression was induced after the activation of the NMDA receptor, followed by an increase in the Grin $2 b$ mRNA levels. Our previous studies also indicated that TBR1 directly binds the Grin $2 b$ promoter and controls the expression of luciferase reporter under the control of Grin $2 b$ promoter (Wang et al., 2004a,b; Huang et al., 2010). Taken together, Tbr1 likely contributes to neuronal activation-dependent Grin $2 b$ expression via a positive feedback loop in mature neurons. Interestingly, our recent data demonstrate that Grin $2 b$ induction upon behavioral stimulation is impaired in $\mathrm{Tbr} \mathrm{1}^{+/-}$mice, which thus show autism-like behaviors (Huang etal., 2014). Because the reduction of Grin $2 b$ likely leads to the deregulation or hypo-activation of NMDAR activity, it then results in an aberrant excitation/inhibition balance. Because the excitation/inhibition imbalance in the brain is highly associated with ASD (Rubenstein and Merzenich, 2003; Won et al., 2012), the impairment of neuronal activation in $\mathrm{Tbr}^{+/}-$mice likely cannot trigger Tbr1 upregulation and thus cause the lack of Grin $2 b$ induction. Therefore, these findings support the hypothesis that neuronal activation-dependent Tbr1 upregulation plays critical roles in the regulation of its target genes relevant to synaptic modification, learning, memory, and psychiatric disorders. Tbr1 has been indicated as high-confidence risk gene for ASDs (Neale et al., 2012; O’Roak et al., 2012a; Huang et al., 2014). In addition to truncated mutants, two missense mutations, $\mathrm{N} 374 \mathrm{H}$ and K228E, had been identified in patients with ASD (Neale et al., 2012; O'Roak etal., 2012b). Our previous studies indicated that the $\mathrm{N} 374 \mathrm{H}$ mutation impairs the ability of Tbr1 to control the differentiation of amygdalar neurons (Huang et al., 2014). However, whether these autism-linked mutants of Tbr1 disrupt the ability of Tbr1 to sense neuronal activation signals and whether the $\mathrm{N} 374 \mathrm{H}$ mutation influences the DNA binding ability or protein stability to further affect TBR1 function remains unclear. Further investigation is needed to elucidate these possibilities.

Note that we reported in an earlier study that NMDA stimulation results in a decrease of Grin2b in neurons (Wang et al., 2004a). Our data presented here indicate that Grin $2 b$ expression is upregulated after the activation of the NMDA receptor. This difference is likely due to the degree of activation of the NMDA receptor. In our previous study, $100 \mu \mathrm{M}$ NMDA was used to stimulate neurons, while $10 \mu \mathrm{M}$ NMDA was applied in the current study. 
Because low-dose NMDA leads to the phosphorylation and highdose NMDA induces de-phosphorylation of CAMKII $\alpha$ at Thr286 (Bozdagi et al., 2010), the opposite effect on CaMKII phosphorylation may then lead to different consequence in terms of Grin $2 b$ expression.

Another interesting data observed in this report is that only treatment with bicuculline, but not NMDA, significantly increased the expression of Grin $2 b$ right after $6 \mathrm{~h}$ stimulation. Bicuculline administration blocks the inhibitory effect of $\mathrm{GABA}_{\mathrm{A}}$ receptors, one of major receptors existed in interneurons, and indirectly promotes excitatory synaptic transmission mediated mainly by glutamatergic neurotransmission (Ferraro et al., 1999; Ch'ng et al., 2012). All of ionotropic glutamate receptors (NMDAR, AMPAR, and kainate receptors), metabotropic glutamate receptors and voltage-gated calcium channels can be indirectly activated by bicuculline and lead to calcium influx (Niciu etal., 2012; Banerjee etal., 2013). However, NMDA is a specific agonist for NMDA receptor and has no action on other glutamate receptors. Our condition $(10 \mu \mathrm{M}$ NMDA for 6 h) may not be strong enough to induce Grin2b expression.

In conclusion, our study showed that neuronal activation increases the mRNA and protein levels of Tbr1 via NMDARdependent activation. The upregulated TBR1 expression then promotes the expression of Grin $2 b$ in mature neurons and adult mice. This study elucidates the physiological significance of $\mathrm{Tbr} 1$ in adult brains and suggests the potential involvement of the activity-dependent upregulation of Tbr1 in cognition.

\section{AUTHOR CONTRIBUTIONS}

Hsiu-Chun Chuang designed and performed all of the experiments, analyzed the results, and drafted the manuscript. Tzyy-Nan Huang contributed to promoter analysis and discussion. Yi-Ping Hsueh designed the experiments and drafted the manuscript. All of the authors read and approved the final version of manuscript.

\section{ACKNOWLEDGMENTS}

We thank Profs. John Rubenstein and Robert Hevner for the $\mathrm{Tbrl}^{+/-}$mice, the Genomic Core of the Institute of Molecular Biology, Academia Sinica, for the technical assistance and members of the Hsueh lab for relabeling samples for the blind test. This work was supported by grants from the Academia Sinica (AS-103- TP-B05 to Yi-Ping Hsueh) and the Ministry of Science and Technology (MOST 102-2321-B-001-029, 102-2321-B-001054, 103-2321-B-001-002, and 103-2321-B-001-018 to Yi-Ping Hsueh).

\section{REFERENCES}

Banerjee, A., Romero-Lorenzo, E., and Sur, M. (2013). MeCP2: making sense of missense in Rett syndrome. Cell Res. 23, 1244-1246. doi: 10.1038/cr.2013.109

Bedogni, F., Hodge, R. D., Elsen, G. E., Nelson, B. R., Daza, R. A., Beyer, R. P., et al. (2010). Tbr1 regulates regional and laminar identity of postmitotic neurons in developing neocortex. Proc. Natl. Acad. Sci. U.S.A. 107, 13129-13134. doi: 10.1073/pnas.1002285107

Benekareddy, M., Nair, A. R., Dias, B. G., Suri, D., Autry, A. E., Monteggia, L. M., et al. (2013). Induction of the plasticity-associated immediate early gene Arc by stress and hallucinogens: role of brain-derived neurotrophic factor. Int. J. Neuropsychopharmacol. 16, 405-415. doi: 10.1017/s1461145712000168
Berretta, S., Parthasarathy, H. B., and Graybiel, A. M. (1997). Local release of GABAergic inhibition in the motor cortex induces immediate-early gene expression in indirect pathway neurons of the striatum. J. Neurosci. 17, 4752-4763.

Bozdagi, O., Sakurai, T., Papapetrou, D., Wang, X., Dickstein, D. L., Takahashi, N., et al. (2010). Haploinsufficiency of the autism-associated Shank3 gene leads to deficits in synaptic function, social interaction, and social communication. Mol. Autism 1:15. doi: 10.1186/2040-2392-1-15

Bulfone, A., Smiga, S. M., Shimamura, K., Peterson, A., Puelles, L., and Rubenstein, J. L. (1995). T-brain-1: a homolog of Brachyury whose expression defines molecularly distinct domains within the cerebral cortex. Neuron 15, 63-78. doi: 10.1016/0896-6273(95)90065-9

Bulfone, A., Wang, F., Hevner, R., Anderson, S., Cutforth, T., Chen, S., et al. (1998). An olfactory sensory map develops in the absence of normal projection neurons or GABAergic interneurons. Neuron 21, 1273-1282. doi: 10.1016/S0896-6273(00)80647-9

Buttner, N., Johnsen, S. A., Kugler, S., and Vogel, T. (2010). Af9/Mllt3 interferes with Tbrl expression through epigenetic modification of histone H3K79 during development of the cerebral cortex. Proc. Natl. Acad. Sci. U.S.A. 107, 7042-7047. doi: 10.1073/pnas.0912041107

Carlisle, H. J., and Kennedy, M. B. (2005). Spine architecture and synaptic plasticity. Trends Neurosci. 28, 182-187. doi: 10.1016/j.tins.2005.01.008

Ch'ng, T. H., Uzgil, B., Lin, P., Avliyakulov, N. K., O’Dell, T. J., and Martin, K. C. (2012). Activity-dependent transport of the transcriptional coactivator CRTC1 from synapse to nucleus. Cell 150, 207-221. doi: 10.1016/j.cell.2012.05.027

Day, J. J., and Sweatt, J. D. (2010). DNA methylation and memory formation. Nat. Neurosci. 13, 1319-1323. doi: 10.1038/nn.2666

de Kloet, E. R., Joels, M., and Holsboer, F. (2005). Stress and the brain: from adaptation to disease. Nat. Rev. Neurosci. 6, 463-475. doi: 10.1038/nrn1683

Felix-Ortiz, A. C., and Tye, K. M. (2014). Amygdala inputs to the ventral hippocampus bidirectionally modulate social behavior. J. Neurosci. 34, 586-595. doi: 10.1523/jneurosci.4257-13.2014

Ferraro, L., Antonelli, T., Tanganelli, S., O’Connor, W. T., Perez De La Mora, M., Mendez-Franco, J., et al. (1999). The vigilance promoting drug modafinil increases extracellular glutamate levels in the medial preoptic area and the posterior hypothalamus of the conscious rat: prevention by local GABAA receptor blockade. Neuropsychopharmacology 20, 346-356. doi: 10.1016/s0893$133 \times(98) 00085-2$

Friberg, H., Ferrand-Drake, M., Bengtsson, F., Halestrap, A. P., and Wieloch, T. (1998). Cyclosporin A, but not FK 506, protects mitochondria and neurons against hypoglycemic damage and implicates the mitochondrial permeability transition in cell death. J. Neurosci. 18, 5151-5159.

Fumagalli, F., Caffino, L., Vogt, M. A., Frasca, A., Racagni, G., Sprengel, R., et al. (2011). AMPA GluR-A receptor subunit mediates hippocampal responsiveness in mice exposed to stress. Hippocampus 21, 1028-1035. doi: 10.1002/hipo. 20817

Greer, P. L., and Greenberg, M. E. (2008). From synapse to nucleus: calciumdependent gene transcription in the control of synapse development and function. Neuron 59, 846-860. doi: 10.1016/j.neuron.2008.09.002

Han, W., Kwan, K. Y., Shim, S., Lam, M. M., Shin, Y., Xu, X., et al. (2011). TBR1 directly represses Fezf2 to control the laminar origin and development of the corticospinal tract. Proc. Natl. Acad. Sci. U.S.A. 108, 3041-3046. doi: 10.1073/pnas. 1016723108

Hao, S., Kurosaki, T., and August, A. (2003). Differential regulation of NFAT and SRF by the B cell receptor via a PLCgamma-Ca(2+)-dependent pathway. EMBO J. 22, 4166-4177. doi: 10.1093/emboj/cdg401

Hardingham, G. E., Fukunaga, Y., and Bading, H. (2002). Extrasynaptic NMDARs oppose synaptic NMDARs by triggering CREB shut-off and cell death pathways. Nat. Neurosci. 5, 405-414. doi: 10.1038/nn835

Hevner, R. F., Shi, L., Justice, N., Hsueh, Y., Sheng, M., Smiga, S., et al. (2001). Tbr1 regulates differentiation of the preplate and layer 6. Neuron 29, 353-366. doi: 10.1016/S0896-6273(01)00211-2

Hong, C. J., and Hsueh, Y. P. (2007). Cytoplasmic distribution of T-box transcription factor Tbr-1 in adult rodent brain. J. Chem. Neuroanat. 33, 124-130. doi: 10.1016/j.jchemneu.2007.01.005

Hsueh, Y. P. (2009). Calcium/calmodulin-dependent serine protein kinase and mental retardation. Ann. Neurol. 66, 438-443. doi: 10.1002/ ana. 21755 
Hsueh, Y. P., Wang, T. F., Yang, F. C., and Sheng, M. (2000). Nuclear translocation and transcription regulation by the membrane-associated guanylate kinase CASK/LIN-2. Nature 404, 298-302. doi: 10.1038/35005118

Huang, F., Chotiner, J. K., and Steward, O. (2007). Actin polymerization and ERK phosphorylation are required for Arc/Arg3.1 mRNA targeting to activated synaptic sites on dendrites. J. Neurosci. 27, 9054-9067. doi: 10.1523/jneurosci.241007.2007

Huang, T. N., Chang, H. P., and Hsueh, Y. P. (2010). CASK phosphorylation by PKA regulates the protein-protein interactions of CASK and expression of the NMDAR2b gene. J. Neurochem. 112, 1562-1573. doi: 10.1111/j.14714159.2010.06569.x

Huang, T. N., Chuang, H. C., Chou, W. H., Chen, C. Y., Wang, H. F., Chou, S. J., et al. (2014). Tbr1 haploinsufficiency impairs amygdalar axonal projections and results in cognitive abnormality. Nat. Neurosci. 17, 240-247. doi: 10.1038/nn.3626

Hughes, P., and Dragunow, M. (1995). Induction of immediate-early genes and the control of neurotransmitter-regulated gene expression within the nervous system. Pharmacol. Rev. 47, 133-178.

Kaminska, B., Figiel, I., Pyrzynska, B., Czajkowski, R., and Mosieniak, G. (2001). Treatment of hippocampal neurons with cyclosporin A results in calcium overload and apoptosis which are independent on NMDA receptor activation. Br. J. Pharmacol. 133, 997-1004. doi: 10.1038/sj.bjp.0704177

Kandel, E. R. (2012). The molecular biology of memory: cAMP, PKA, CRE, CREB-1, CREB-2, and CPEB. Mol. Brain 5:14. doi: 10.1186/1756-6606-5-14

King, I. F., Yandava, C. N., Mabb, A. M., Hsiao, J. S., Huang, H. S., Pearson, B. L., et al. (2013). Topoisomerases facilitate transcription of long genes linked to autism. Nature 501, 58-62. doi: 10.1038/nature12504

Kristiansen, L. V., Patel, S. A., Haroutunian, V., and Meador-Woodruff, J. H. (2010). Expression of the NR2B-NMDA receptor subunit and its Tbr-1/CINAP regulatory proteins in postmortem brain suggest altered receptor processing in schizophrenia. Synapse 64, 495-502. doi: 10.1002/syn.20754

Lesscher, H. M., Mcmahon, T., Lasek, A. W., Chou, W. H., Connolly, J., Kharazia, V., et al. (2008). Amygdala protein kinase C epsilon regulates corticotropinreleasing factor and anxiety-like behavior. Genes Brain Behav. 7, 323-333. doi: 10.1111/j.1601-183X.2007.00356.x

Lieberman, D. N., and Mody, I. (1994). Regulation of NMDA channel function by endogenous $\mathrm{Ca}(2+)$-dependent phosphatase. Nature 369, 235-239. doi: $10.1038 / 369235 \mathrm{a} 0$

Medina, L., Legaz, I., Gonzalez, G., De Castro, F., Rubenstein, J. L., and Puelles, L. (2004). Expression of Dbx1, Neurogenin 2, Semaphorin 5A, Cadherin 8, and Emxl distinguish ventral and lateral pallial histogenetic divisions in the developing mouse claustroamygdaloid complex. J. Comp. Neurol. 474, 504-523. doi: $10.1002 / \mathrm{cne} .20141$

Montag-Sallaz, M., Welzl, H., Kuhl, D., Montag, D., and Schachner, M. (1999). Novelty-induced increased expression of immediate-early genes c-fos and arg 3.1 in the mouse brain. J. Neurobiol. 38, 234-246. doi: 10.1002/(SICI)10974695(19990205)38:2<234::AID-NEU6>3.0.CO;2-G

Moog, U., Kutsche, K., Kortum, F., Chilian, B., Bierhals, T., Apeshiotis, N., et al. (2011). Phenotypic spectrum associated with CASK loss-of-function mutations. J. Med. Genet. 48, 741-751. doi: 10.1136/jmedgenet-2011-100218

Najm, J., Horn, D., Wimplinger, I., Golden, J. A., Chizhikov, V. V., Sudi, J., et al. (2008). Mutations of CASK cause an X-linked brain malformation phenotype with microcephaly and hypoplasia of the brainstem and cerebellum. Nat. Genet. 40, 1065-1067. doi: 10.1038/ng.194

Neale, B. M., Kou, Y., Liu, L., Ma’ayan, A., Samocha, K. E., Sabo, A., et al. (2012). Patterns and rates of exonic de novo mutations in autism spectrum disorders. Nature 485, 242-245. doi: 10.1038/nature11011

Niciu, M. J., Kelmendi, B., and Sanacora, G. (2012). Overview of glutamatergic neurotransmission in the nervous system. Pharmacol. Biochem. Behav. 100, 656664. doi: 10.1016/j.pbb.2011.08.008

O’Roak, B. J., Vives, L., Fu, W., Egertson, J. D., Stanaway, I. B., Phelps, I. G., et al. (2012a). Multiplex targeted sequencing identifies recurrently mutated genes in autism spectrum disorders. Science 338, 1619-1622. doi: 10.1126/science. 1227764

O’Roak, B. J., Vives, L., Girirajan, S., Karakoc, E., Krumm, N., Coe, B. P., et al. (2012b). Sporadic autism exomes reveal a highly interconnected protein network of de novo mutations. Nature 485, 246-250. doi: 10.1038/nature10989

Parkes, S. L., and Westbrook, R. F. (2011). Role of the basolateral amygdala and NMDA receptors in higher-order conditioned fear. Rev. Neurosci. 22, 317-333. doi: $10.1515 /$ RNS.2011.025
Park, J. B., Kim, E. J., Yang, E. J., Seo, S. R., and Chung, K. C. (2007). JNK- and Racl-dependent induction of immediate early gene pip92 suppresses neuronal differentiation. J. Neurochem. 100, 555-566. doi: 10.1111/j.14714159.2006.04263.x

Pfeiffer, B. E., Zang, T., Wilkerson, J. R., Taniguchi, M., Maksimova, M. A., Smith, L. N., et al. (2010). Fragile X mental retardation protein is required for synapse elimination by the activity-dependent transcription factor MEF2. Neuron 66, 191-197. doi: 10.1016/j.neuron.2010.03.017

Piette, C. E., Baez-Santiago, M. A., Reid, E. E., Katz, D. B., and Moran, A. (2012). Inactivation of basolateral amygdala specifically eliminates palatabilityrelated information in cortical sensory responses. J. Neurosci. 32, 9981-9991. doi: 10.1523/jneurosci.0669-12.2012

Popoli, M., Yan, Z., Mcewen, B. S., and Sanacora, G. (2012). The stressed synapse: the impact of stress and glucocorticoids on glutamate transmission. Nat. Rev. Neurosci. 13, 22-37. doi: 10.1038/nrn3138

Ramanan, N., Shen, Y., Sarsfield, S., Lemberger, T., Schutz, G., Linden, D. J., et al. (2005). SRF mediates activity-induced gene expression and synaptic plasticity but not neuronal viability. Nat. Neurosci. 8, 759-767. doi: 10.1038/ nn 1462

Remedios, R., Huilgol, D., Saha, B., Hari, P., Bhatnagar, L., Kowalczyk, T., et al. (2007). A stream of cells migrating from the caudal telencephalon reveals a link between the amygdala and neocortex. Nat. Neurosci. 10, 1141-1150. doi: 10.1038/nn1955

Revest, J. M., Di Blasi, F., Kitchener, P., Rouge-Pont, F., Desmedt, A., Turiault, M., et al. (2005). The MAPK pathway and Egr-1 mediate stress-related behavioral effects of glucocorticoids. Nat. Neurosci. 8, 664-672. doi: 10.1038/ nn 1441

Rial Verde, E. M., Lee-Osbourne, J., Worley, P. F., Malinow, R., and Cline, H. T. (2006). Increased expression of the immediate-early gene arc/arg3.1 reduces AMPA receptor-mediated synaptic transmission. Neuron 52, 461-474. doi: 10.1016/j.neuron.2006.09.031

Rubenstein, J. L., and Merzenich, M. M. (2003). Model of autism: increased ratio of excitation/inhibition in key neural systems. Genes Brain Behav. 2, 255-267. doi: 10.1034/j.1601-183X.2003.00037.x

Saneyoshi, T., and Hayashi, Y. (2012). The $\mathrm{Ca}^{2+}$ and Rho GTPase signaling pathways underlying activity-dependent actin remodeling at dendritic spines. Cytoskeleton (Hoboken) 69, 545-554. doi: 10.1002/cm.21037

Schwartz, N., Schohl, A., and Ruthazer, E. S. (2009). Neural activity regulates synaptic properties and dendritic structure in vivo through calcineurin/NFAT signaling. Neuron 62, 655-669. doi: 10.1016/j.neuron.2009. 05.007

Sheng, M., and Greenberg, M. E. (1990). The regulation and function of c-fos and other immediate early genes in the nervous system. Neuron 4, 477-485. doi: 10.1016/0896-6273(90)90106-P

Soderling, T. R., and Derkach, V. A. (2000). Postsynaptic protein phosphorylation and LTP. Trends Neurosci. 23, 75-80. doi: 10.1016/S0166-2236(99) 01490-3

Stevenson, D. A., Yan, J., He, Y., Li, H., Liu, Y., Zhang, Q., et al. (2011). Multiple increased osteoclast functions in individuals with neurofibromatosis type 1. Am. J. Med. Genet. A 155, 1050-1059. doi: 10.1002/ajmg.a.33965

Tarpey, P. S., Smith, R., Pleasance, E., Whibley, A., Edkins, S., Hardy, C., et al. (2009). A systematic, large-scale resequencing screen of X-chromosome coding exons in mental retardation. Nat. Genet. 41, 535-543. doi: 10.1038/ ng.367

Tolias, K. F., Duman, J. G., and Um, K. (2011). Control of synapse development and plasticity by Rho GTPase regulatory proteins. Prog. Neurobiol. 94, 133-148. doi: 10.1016/j.pneurobio.2011.04.011

Victor, R. G., Thomas, G. D., Marban, E., and O'Rourke, B. (1995). Presynaptic modulation of cortical synaptic activity by calcineurin. Proc. Natl. Acad. Sci. U.S.A. 92, 6269-6273. doi: 10.1073/pnas.92. 14.6269

Wang, G. S., Hong, C. J., Yen, T. Y., Huang, H. Y., Ou, Y., Huang, T. N., et al. (2004a). Transcriptional modification by a CASK-interacting nucleosome assembly protein. Neuron 42, 113-128. doi: 10.1016/S0896-6273(04) 00139-4

Wang, T. F., Ding, C. N., Wang, G. S., Luo, S. C., Lin, Y. L., Ruan, Y., et al. (2004b). Identification of Tbr-1/CASK complex target genes in neurons. J. Neurochem. 91, 1483-1492. doi: 10.1111/j.1471-4159.2004.02845.x 
Weickert, C. S., Fung, S. J., Catts, V. S., Schofield, P. R., Allen, K. M., Moore, L. T., et al. (2013). Molecular evidence of $N$-methyl-D-aspartate receptor hypofunction in schizophrenia. Mol. Psychiatry 18, 1185-1192. doi: 10.1038/mp. 2012.137

Won, H., Lee, H. R., Gee, H. Y., Mah, W., Kim, J. I., Lee, J., et al. (2012). Autistic-like social behaviour in Shank2-mutant mice improved by restoring NMDA receptor function. Nature 486, 261-265. doi: 10.1038/nature11208

Yuen, E. Y., Liu, W., Karatsoreos, I. N., Ren, Y., Feng, J., Mcewen, B. S., et al. (2011). Mechanisms for acute stress-induced enhancement of glutamatergic transmission and working memory. Mol. Psychiatry 16, 156-170. doi: 10.1038/ mp. 2010.50

Zhang, X., Odom, D. T., Koo, S. H., Conkright, M. D., Canettieri, G., Best, J., et al. (2005). Genome-wide analysis of cAMP-response element binding protein occupancy, phosphorylation, and target gene activation in human tissues. Proc. Natl. Acad. Sci. U.S.A. 102, 4459-4464. doi: 10.1073/pnas. 0501076102
Conflict of Interest Statement: The authors declare that the research was conducted in the absence of any commercial or financial relationships that could be construed as a potential conflict of interest.

Received: 23 June 2014; accepted: 24 August 2014; published online: 10 September 2014.

Citation: Chuang H-C, Huang T-N and Hsueh Y-P (2014) Neuronal excitation upregulates Tbr1, a high-confidence risk gene of autism, mediating Grin $2 b$ expression in the adult brain. Front. Cell. Neurosci. 8:280. doi: 10.3389/fncel.2014.00280

This article was submitted to the journal Frontiers in Cellular Neuroscience. Copyright ( $(2014$ Chuang, Huang and Hsueh. This is an open-access article distributed under the terms of the Creative Commons Attribution License (CC BY). The use, distribution or reproduction in other forums is permitted, provided the original author(s) or licensor are credited and that the original publication in this journal is cited, in accordance with accepted academic practice. No use, distribution or reproduction is permitted which does not comply with these terms. 